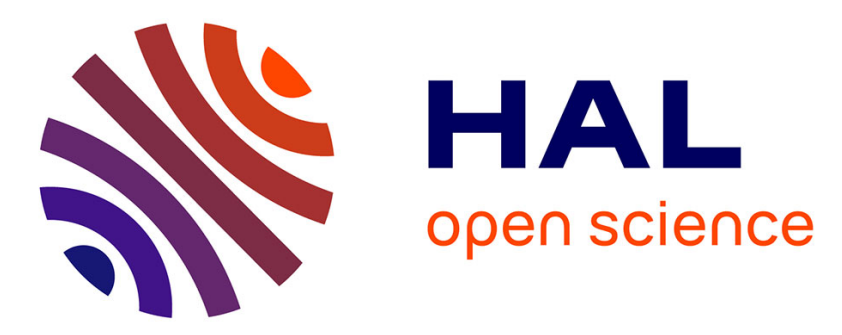

\title{
A large-conductance calcium-activated potassium channel in potato tuber mitochondria
}

Izabela Koszela-Piotrowska, Karolina Matkovic, Adam Szewczyk, Wieslawa

Jarmuszkiewicz

\section{- To cite this version:}

Izabela Koszela-Piotrowska, Karolina Matkovic, Adam Szewczyk, Wieslawa Jarmuszkiewicz. A largeconductance calcium-activated potassium channel in potato tuber mitochondria. Biochemical Journal, 2009, 424 (2), pp.307-316. 10.1042/BJ20090991 . hal-00479217

\section{HAL Id: hal-00479217 https://hal.science/hal-00479217}

Submitted on 30 Apr 2010

HAL is a multi-disciplinary open access archive for the deposit and dissemination of scientific research documents, whether they are published or not. The documents may come from teaching and research institutions in France or abroad, or from public or private research centers.
L'archive ouverte pluridisciplinaire HAL, est destinée au dépôt et à la diffusion de documents scientifiques de niveau recherche, publiés ou non, émanant des établissements d'enseignement et de recherche français ou étrangers, des laboratoires publics ou privés. 


\title{
A Large-Conductance Calcium-Activated Potassium Channel in Potato Tuber Mitochondria
}

\section{Izabela KOSZELA-PIOTROWSKA ${ }^{\#, a}$, Karolina MATKOVIC ${ }^{\#, b}$, Adam SZEWCZYK ${ }^{\mathrm{a}, 1}$ and Wieslawa JARMUSZKIEWICZ ${ }^{\mathrm{b}}$}

${ }^{a}$ Laboratory of Intracellular Ion Channels, Nencki Institute of Experimental Biology, 3 Pasteur st., 02-093 Warsaw, Poland, ${ }^{b}$ Laboratory of Bioenergetics, Faculty of Biology, Adam Mickiewicz University, Poznan, Poland

Short title: Calcium-activated potassium channel in plant mitochondria

\# These authors contributed equally to this work

To whom correspondence should be addressed: Adam Szewczyk, Laboratory of Intracellular Ion Channels, Nencki Institute of Experimental Biology, 3 Pasteur St., 02-093 Warsaw, Poland, Tel.: +48225892269; Fax: +48228225342; E-mail: adam@nencki.gov.pl

\begin{abstract}
Abbreviations used: $\mathrm{BK}_{\mathrm{Ca}}$ channel, plasma membrane large-conductance $\mathrm{Ca}^{2+}$-activated potassium channel; BSA, bovine serum albumin; IbTx, iberiotoxin; KCOs, potassium channel openers; mitoBK $_{\mathrm{Ca}}$ channel, mitochondrial large-conductance $\mathrm{Ca}^{2+}$-activated potassium channel; mitoK $\mathrm{ATP}_{\text {ATP }}$ channel, mitochondrial ATP-sensitive potassium channel; NS1619, 1,3-dihydro-1-[2-hydroxy-5(trifluoromethyl)phenyl]-5-(trifluoromethyl)-2H-benzimidazole-2-one; PLM, planar lipid membrane; SMP, submitochondrial particles; $\mathrm{TPP}^{+}$, tetraphenylphosphonium $\Delta \Psi$, mitochondrial transmembrane electrical potential
\end{abstract}

Key words: bioenergetics; electrophysiology; mitochondria; potassium channel; Solanum tuberosum; 
Synopsis

In the present study, we describe the existence of a novel potassium channel in the plant (potato tuber) mitochondrial inner membrane. We found that substances known to modulate large-conductance calciumactivated potassium channel activity influenced the bioenergetics of potato tuber mitochondria. In isolated mitochondria, $\mathrm{Ca}^{2+}$ and NS1619 (a potassium channel opener) were found to depolarize the mitochondrial membrane potential and to stimulate resting respiration. These effects were blocked by iberiotoxin (a potassium channel inhibitor) in a potassium-dependent manner. Additionally, the electrophysiological properties of the large-conductance potassium channel present in the potato tuber inner mitochondrial membrane are described in a reconstituted system, using planar lipid bilayers. After incorporation in 50/450 $\mathrm{mM} \mathrm{KCl}$ gradient solutions, we recorded large-conductance potassium channel activity with conductance from $502 \pm 15$ to $615 \pm 12 \mathrm{pS}$. The probability of channel opening was increased by $\mathrm{Ca}^{2+}$ and reduced by iberiotoxin. Immunological analysis with antibodies raised against the mammalian plasma membrane largeconductance $\mathrm{Ca}^{2+}$-dependent $\mathrm{K}^{+}$channel identified a pore-forming $\alpha$ subunit and an auxiliary $\beta 2$ subunit of the channel in potato tuber mitochondrial inner membrane. These results suggest that a large-conductance calcium-activated potassium channel similar to that of mammalian mitochondria is present in potato tuber mitochondria. 


\section{INTRODUCTION}

Mitochondria play an important role in energy metabolism within the cell. In addition to this canonical function, mitochondria are involved in intracellular signaling. Recently, potassium transport through the mitochondrial inner membrane was found to play a central role in the cytoprotection of various mammalian cell types [1,2]. This transport is strictly ion channel-dependent. Similarly to the plasma membrane, potassium-selective ion channels are found in the inner mitochondrial membrane [3-5]. Potassium ions control mitochondrial metabolism, primarily via a regulation of matrix volume [6]. The biophysical and pharmacological properties of mitochondrial potassium channels are similar to some of the potassium channels present in the plasma membrane of various mammalian cell types, for example mitochondrial ATP-regulated potassium channels (mitoK $\mathrm{ATP}_{\text {AT }}$ channels) [7], large-conductance calcium-activated potassium channels (mitoBK $\mathrm{Ca}_{\mathrm{Ca}}$ channels) [8], and voltage-dependent potassium Kv1.3 channels [9].

In plant mitochondria, the existence of different energy-dissipating systems is necessary for metabolic regulation [10]. Plant mitochondria (but not animal mitochondria) contain an alternative oxidase (AOX) that catalyses ubiquinol-oxygen oxidoreduction without $\mathrm{H}^{+}$release into the cytosol, thus dissipating the redox potential energy $[11,12]$. Similarly to animal mitochondria, plant mitochondria contain an uncoupling protein (PUMP) that dissipates a proton electrochemical gradient by mediating re-entry of $\mathrm{H}^{+}$into the mitochondrial matrix in the presence of free fatty acids [13]. Another energy-dissipating system present in plant mitochondria (as in animal mitochondria) is the ATP-sensitive potassium channel ( mitoK $_{\text {ATP }}$ channel), which mediates an electrophoretic $\mathrm{K}^{+}$uniport, likely working together with an electroneutral $\mathrm{K}^{+} / \mathrm{H}^{+}$ exchanger [14-17]. Descriptions of the plant mitoK $\mathrm{ATP}_{\mathrm{A}}$ channel have been based mainly on studies of isolated mitochondria in which the influence of $\mathrm{K}^{+}$entry into the mitochondrial matrix on membrane potential $(\Delta \Psi)$ dissipation and mitochondrial swelling were assessed. The plant mitoK $\mathrm{K}_{\mathrm{ATP}}$ channel seems to be sensitive to the same potassium channel modulators as the mammalian mitoK $_{\mathrm{ATP}}$ channel. In durum wheat and pea mitochondria, the mitoK $\mathrm{K}_{\mathrm{ATP}}$ channel is activated by diazoxide and GTP, and its activity is inhibited by glyburide and 5-hydroxydecanoate (in pea mitochondria) [14,16,18]. Moreover, the plant mitoK $_{\text {ATP }}$ appears to be stimulated by cyclosporin A and regulated by dithiol-disulfide interconversion, $\mathrm{H}_{2} \mathrm{O}_{2}$, and NO $[15,16,19]$. On the other hand, an ATP-insensitive, quinine-inhibited potassium import pathway has been described in potato, tomato, and maize mitochondria [20].

So far, there has been no information about other possible plant mitochondrial potassium channels, such as the large-conductance $\mathrm{Ca}^{2+}$-activated potassium channel (mitoBK $\mathrm{Ca}$ channel) described in animal mitochondria. Therefore, the aim of this study was to search for a mitoBK $\mathrm{Ca}_{\mathrm{Ca}}$ channel in plant mitochondria and to determine the bioenergetic consequences of its activation. For this purpose, we studied the effects of $\mathrm{BK}_{\mathrm{Ca}}$ channel activators $\left(\mathrm{Ca}^{2+}, \mathrm{NS1619}\right)$ and inhibitor (iberiotoxin, IbTx) on $\Delta \Psi$ and respiration in isolated potato tuber mitochondria. Moreover, measurements of the electrophysiological properties of a single mitoBK $_{\mathrm{Ca}}$ channel in a reconstituted system were carried out and immunological detection experiments were performed to confirm the discovery of a plant mitoBK $_{\mathrm{Ca}}$ channel.

\section{EXPERIMENTAL \\ Chemicals}

L- $\alpha$-phosphatidyl-choline (asolectin), NS1619, and $n$-decane were purchased from Sigma-Aldrich, and IbTx from Bachem. All other chemicals were of the highest purity commercially available. NS1619 was dissolved in methanol, and $\mathrm{IbTx}$ in $\mathrm{H}_{2} \mathrm{O}$.

\section{Isolation of mitochondria}

Potato (Solanum tuberosum) tubers were purchased from the local supermarket. One kilogram of peeled potato tubers were homogenized in a blender in 1 liter of ice-cold medium consisting of $0.35 \mathrm{M}$ mannitol, 3

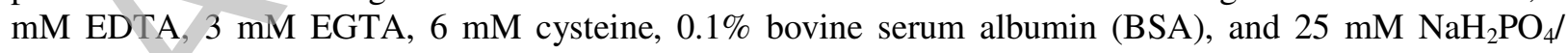
$\mathrm{Na}_{2} \mathrm{HPO}_{4}$ buffer. The $\mathrm{pH}$ was adjusted to 8.0 with $\mathrm{NaOH}$. The crude extract was quickly filtered through cheesecloth, and the filtrate was centrifuged at $1000 \mathrm{x}$ g for $10 \mathrm{~min}$. The supernatant was further centrifuged at $11000 \mathrm{x} \mathrm{g}$ for $20 \mathrm{~min}$. The pellet of crude mitochondria was washed with medium consisting of $0.35 \mathrm{M}$ mannitol, $1.5 \mathrm{mM}$ EGTA, 0.1\% BSA, and $10 \mathrm{mM} \mathrm{NaH}{ }_{2} \mathrm{PO}_{4} / \mathrm{Na}_{2} \mathrm{HPO} 4$ buffer $(\mathrm{pH}$ 6.8) and centrifuged 
again at $1000 \mathrm{x} \mathrm{g}$ for $5 \mathrm{~min}$ and then at $11000 \mathrm{xg}$ for $20 \mathrm{~min}$. Mitochondria were subsequently purified on a self-generating $22 \%$ Percoll gradient (at $40000 \mathrm{x}$ g for $30 \mathrm{~min}$ ). Purified mitochondria were washed twice in the same medium without EGTA and BSA. The mitochondrial protein concentration was determined by the biuret method.

\section{Preparation of membrane fractions}

To obtain submitochondrial particles (SMP), mitochondria were isolated as above, but with media of $\mathrm{K}^{+}$ salts. Freshly prepared mitochondria were diluted to about $8 \mathrm{mg}$ of protein $/ \mathrm{ml}$ with $0.3 \mathrm{M}$ sucrose and 10 $\mathrm{mM}$ Hepes- $\mathrm{KOH}, \mathrm{pH} 7.2$, and subsequently frozen at $-20^{\circ} \mathrm{C}$. After thawing, the suspension was sonicated 6 times for $30 \mathrm{~s}$ and centrifuged at $12000 \times \mathrm{g}$ for $15 \mathrm{~min}$ to pellet the unbroken mitochondria. The supernatant was centrifuged at $200000 \times \mathrm{g}(2 \mathrm{~h})$ to pellet SMP. Fractions of SMP, which are the mitochondrial inner membrane-enriched fractions, were resuspended in $0.3 \mathrm{M}$ sucrose and $10 \mathrm{mM}$ Hepes- $\mathrm{KOH}, \mathrm{pH} 7.2$ at a concentration of $5 \mathrm{mg}$ of protein $/ \mathrm{ml}$.

To obtain a plasma membrane-enriched fraction, the supernatant from the first $11000 \mathrm{x} g$ centrifugation during mitochondria isolation was centrifuged at $100000 \mathrm{x}$ g for $1 \mathrm{~h}$. The pellet was resuspended in $0.3 \mathrm{M}$ sucrose and $10 \mathrm{mM}$ Hepes-KOH, $\mathrm{pH}$ 7.2.

\section{Planar lipid membrane (PLM) measurements}

Experiments were performed with potato tuber SMP, as described previously [21-23]. In brief, PLMs were formed in a $250-\mu \mathrm{m}$-diameter hole drilled in a Delrin cup (Warner Instrument, CT), which separates the two chambers (cis and trans, each with a $1-\mathrm{ml}$ internal volume). The chambers contained $50 / 450 \mathrm{mM} \mathrm{KCl}$ (trans/cis) and $20 \mathrm{mM}$ Tris- $\mathrm{HCl}$ solutions, $\mathrm{pH}$ 7.2. The outline of the aperture was coated with a lipid solution and $\mathrm{N}_{2}$ dried prior to bilayer formation to improve membrane stability. PLMs were painted using asolectin in $n$-decane at a final concentration of $25 \mathrm{mg}$ of lipid/ml. SMP (about $3 \mu \mathrm{g}$ of protein/ml, 0.5-1.5 $\mu 1 /$ reconstitution) were added to the trans compartment (Figure 5A). All measurements were carried out at room temperature $\left(\sim 25^{\circ} \mathrm{C}\right)$. Formation and thinning of the bilayer were monitored by capacitance measurements and optical observations. Final accepted capacitance values ranged from 120 to 230 picofarads. Electrical connections were created using $\mathrm{Ag} / \mathrm{AgCl}$ electrodes and agar salt bridges $(3 \mathrm{M} \mathrm{KCl})$ to minimize liquid junction potentials. Voltage was applied to the cis compartment of the chamber, and the trans compartment was grounded. The current was measured using a bilayer membrane amplifier (BLM120, BioLogic). Signals were low-pass filtered at $500 \mathrm{~Hz}$. The current was digitized at a sampling rate of $100 \mathrm{kHz}$ (A/D converter PowerLab 2/20, ADInstruments) and transferred to a PC for off-line analysis by Chart version 5.5.5 (PowerLab ADInstruments) and pCLAMP10.2 (Axon Instruments). The pCLAMP10.2 software package was used for data processing. The channel recordings presented are representative of the most frequently observed conductance values under the given conditions. Ion conductance was calculated from the linear regression of the points in the current-voltage relationship using the GraphPad Prism 4 program.

\section{Mitochondrial oxygen consumption}

Oxygen uptake was measured polarographically with a Clarck type oxygen electrode (Rank Brothers) in 3 $\mathrm{ml}$ of standard incubation medium $\left(25^{\circ} \mathrm{C}\right)$ consisting of $0.35 \mathrm{M}$ mannitol, $3 \mathrm{mM} \mathrm{NaH} \mathrm{PO}_{4}, 1 \mathrm{mM} \mathrm{MgCl}{ }_{2}$, $10 \mathrm{mM}$ TrisHCl, $10 \mathrm{mM}$ MES, $\mathrm{pH} 6.8$, and $0.1 \%$ BSA. Changes in the composition of the incubation medium are described in the figure legend. Measurements were performed with 0.8-1 mg of mitochondrial protein in the presence of $1.5 \mathrm{mM}$ benzohydroxymate (an inhibitor of alternative oxidase), $0.14 \mathrm{mM}$ ATP (to activate succinate dehydrogenase), $1.8 \mu \mathrm{M}$ carboxyatractylozide (to exclude ATP/ADP antiporter activity), and $10 \mathrm{mM}$ glibenclamide (to inhibit the mitoK $_{\text {ATP }}$ channel). Succinate $(5 \mathrm{mM})$ plus rotenone (2 $\mu \mathrm{M})$ was used as a respiratory substrate. Respiratory rate measurements were performed in the absence of added ADP, i.e., in the resting state (state 4). State 3 (phosphorylating) respiration measurements were performed to check the coupling parameters. Only high quality mitochondria preparations, i.e., with an $\mathrm{ADP} / \mathrm{O}$ value of around 1.40 and a respiratory control ratio of around 2.5-3 (with succinate), were used in all experiments. $\mathrm{O}_{2}$ uptake values are presented in $\mathrm{nmol} \mathrm{O} \times \mathrm{min}^{-1} \times \mathrm{mg}^{-1}$ protein. 


\begin{abstract}
Mitochondrial membrane potential measurements
The mitochondrial $\Delta \Psi$ was measured simultaneously with oxygen uptake using a tetraphenylphosphonium $\left(\mathrm{TPP}^{+}\right)$-specific electrode according to Kamo et al. [24]. Measurements were performed in the presence of 6 $\mu \mathrm{M} \mathrm{TPP}$. To calculate the $\Delta \Psi$ value, the matrix volume of potato tuber mitochondria was assumed to be $2.0 \mu \mathrm{l} \times \mathrm{mg}^{-1}$ protein. The calculation assumes that the $\mathrm{TPP}^{+}$distribution between mitochondria and medium followed the Nernst equation. Corrections were made for $\mathrm{TPP}^{+}$binding to mitochondrial membranes. Values of $\Delta \Psi$ are presented in $\mathrm{mV}$.
\end{abstract}

\title{
SDS-PAGE and immunoblotting
}

Samples of isolated mitochondrial proteins, SMP or the plasma membrane-enriched fraction were solubilized in sample buffer containing $2 \%$ (w/v) SDS, $50 \mathrm{mM}$ Tris/Cl (pH.6.8), $10 \%$ glycerol, $0.004 \%$ (w/v) bromophenol blue, and $8 \%$ mercaptoethanol, and then boiled for 4 min. Proteins were separated in $12.5 \%$ SDS-polyacrylamide gels, and then electrotransferred to a nitrocellulose membrane. Membranes were then hybridized with anti- $\mathrm{K}_{\mathrm{Ca}} 1.1$ and anti-sloß2 antibodies (APC-107 and APC-034, Alomone) at dilutions of 1:500 or 1:200, respectively, in the presence or absence of blocking peptide. Cross reactivity was also checked with antibodies raised against a plant plasma membrane $\mathrm{H}^{+}$-ATPase (at a dilution of 1:1000). Protein detection was achieved with secondary antibodies linked to horseradish peroxidase (at a dilution of 1:20000) and the ECL chemiluminescence system. Protein content was determined by the Bradford method (Bio-Rad).

\section{RESULTS}

Effect of potassium channel modulators on respiratory rate and membrane potential in isolated potato tuber mitochondria

To investigate the possible effects of $\mathrm{Ca}^{2+}$ on the potassium permeability of isolated potato tuber mitochondria, we measured mitochondrial resting (nonphosphorylating) respiration and $\Delta \Psi$ in potassiumcontaining medium in the presence of different $\mathrm{Ca}^{2+}$ concentrations, using succinate as an oxidizable substrate (Figure 1). An example of simultaneous measurements of the respiratory rate and $\Delta \Psi$ is shown in Figure 1A. Addition of $\mathrm{Ca}^{2+}$ up to a concentration of $1 \mathrm{mM}$ caused an increased respiration rate of up to 20 $\pm 2 \%$ in the absence of $1.5 \mu \mathrm{M} \mathrm{IbTx}$, and up to $5 \pm 3 \%$ in its presence $(n=4$, S.D.) (Figure 1C). At the same time, $\Delta \Psi$ decreased after addition of $\mathrm{Ca}^{2+}$ by up to $6.8 \pm 0.5 \mathrm{mV}$ and $0.7 \pm 0.4 \mathrm{mV}$ in the absence and presence of IbTx, respectively ( $n=4$, S.D.) (Figure 1D). Thus, the inhibitor previously described as specific for the mammalian large-conductance potassium channel $[1,2]$ considerably blocks $\mathrm{Ca}^{2+}$-induced respiration and $\Delta \Psi$ depolarization in isolated potato tuber mitochondria. These results suggest that $\mathrm{Ca}^{2+}$ stimulates IbTx-sensitive $\mathrm{K}^{+}$flux into potato tuber mitochondria, decreasing $\Delta \Psi$ and thus accelerating the mitochondrial respiration rate. This indicates that the $\operatorname{mitoBK}_{\mathrm{Ca}}$ channel is present in potato tuber mitochondria. The $\mathrm{Ca}^{2+}$-induced IbTx-sensitive respiratory rate (i.e., the difference between the respiratory rate in the presence of $\mathrm{Ca}^{2+}$ and the rate in the presence of $\mathrm{Ca}^{2+}$ plus inhibitor) should represent mitoBK channel activity (i.e., the channel-mediated $\mathrm{K}^{+}$flux). This activity, as measured using various $\mathrm{Ca}^{2+}$ concentrations (Figure 1B), revealed that $50 \%$ of the maximal stimulation $\left(\mathrm{S}_{0.5}\right)$ by $\mathrm{Ca}^{2+}$ is reached at 0.45 $\mathrm{mM}$, as calculated from the linear regression of a double reciprocal plot (Figure 1B, inset). A similar value was attained when the $\mathrm{Ca}^{2+}$-induced $\mathrm{IbTx}$-sensitive depolarization of $\Delta \Psi$ versus the $\mathrm{Ca}^{2+}$ concentration was analyzed (data not shown). The partial insensitivity of $\mathrm{Ca}^{2+}$-induced respiration and $\Delta \Psi$ depolarization to IbTx observed in potato tuber mitochondria is likely related to electrophoretic $\mathrm{Ca}^{2+}$ influx pathways present in some plant mitochondria [25] or permeability transition opening [26].

The potassium channel opener NS1619, previously described to be specific for the mitoBK $\mathrm{C}_{\mathrm{Ca}}$ channel [1,2], was also used in our studies. Similarly to calcium ions, NS1619 stimulates mitochondrial resting oxygen uptake and decreases mitochondrial resting $\Delta \Psi$ (Figure 2). An example of the effect of increasing concentrations of NS1619 on respiratory rate and $\Delta \Psi$ is shown in Figure 2A. Addition of NS1619 up to 40 $\mu \mathrm{M}$ resulted in an increase in the rate of respiration up to $100 \pm 6 \%$ and $53 \pm 7 \%(n=6$, S.D.) in the 
absence and presence of $1.5 \mu \mathrm{M} \mathrm{IbTx}$, respectively (Figure 2C). At the same time, $\Delta \Psi$ decreased after addition of up to $40 \mu \mathrm{M}$ NS1618 by up to $18.1 \pm 2 \mathrm{mV}$ and $10.6 \pm 1.3 \mathrm{mV}(n=6$, S.D.) in the absence and presence of IbTx, respectively (Figure 2D). Thus, IbTx partially blocks (approximately 50\%) NS1619induced respiration and $\Delta \Psi$ depolarization in isolated potato tuber mitochondria. When compared to the effect of IbTx on $\mathrm{Ca}^{2+}$-induced respiration and $\Delta \Psi$ depolarization (Figure 3), this could indicate a nonspecific uncoupling effect of NS1619 on isolated potato tuber mitochondria rather than low sensitivity of the channel to IbTx. Similarly, the sensitivity of NS1619-induced respiration and $\Delta \Psi$ depolarization to the mitoBK $\mathrm{Ca}_{\mathrm{C}}$ channel blockers (IbTx, charybdotoxin, paxilline) in some mammalian isolated mitochondria is not complete [27-30]. Nevertheless, we can conclude that in potato tuber mitochondria, NS1619 stimulates IbTx-sensitive $\mathrm{K}^{+}$flux, decreases $\Delta \Psi$, and thus accelerates the mitochondrial respiration rate, further indicating the presence of the mitoBK $\mathrm{Ca}_{\mathrm{C}}$ channel activity. The NS1619-induced IbTx-sensitive respiratory rate (i.e., the difference between the respiratory rate in the presence of the modulator and the rate after addition of the inhibitor) measured at various NS1619 concentrations revealed that $50 \%$ of maximal stimulation $\left(\mathrm{S}_{0.5}\right)$ is reached at $25 \mu \mathrm{M}$ NS1619 [Figure 2B, inset]. When NS1619-induced IbTx-sensitive depolarization of $\Delta \Psi$ at various NS1619 concentrations was plotted, a similar value of $S_{0.5}$ for NS1619 was obtained (data not shown).

Figure 3 illustrates the efficiency of $\mathrm{IbTx}$ in the inhibition of mitoBK $\mathrm{Ca}$ channel activity under unstimulated (no activators) or stimulated (in the presence of $0.8 \mathrm{mM} \mathrm{CaCl}_{2}$ or $40 \mu \mathrm{M} \mathrm{NS1619)}$ conditions. An example of the effect of increasing concentrations of IbTX on NS1619-induced respiration and $\Delta \Psi$ depolarization is shown in Figure 3A. Under all studied conditions, addition of IbTx up to a concentration of $1.5 \mu \mathrm{M}$ blocked unstimulated, NS1619-induced, and $\mathrm{Ca}^{2+}$-induced respiration by up to $4 \%$, 53\%, and $79 \%$, respectively (Figure 3C). Similarly, IbTx restored up to $1 \%, 46 \%$ and $78 \%$ of unstimulated, NS1619induced and $\mathrm{Ca}^{2+}$-induced $\Delta \Psi$ depolarization, respectively (Figure 3D). These results indicate low activity of the mitoBK $\mathrm{Ca}_{\mathrm{a}}$ channel in the absence of modulators in isolated potato tuber mitochondria, as $\mathrm{IbTx}$ has a slight inhibitory effect. Moreover, the results reveal that $\mathrm{IbTx}$ inhibits $\mathrm{Ca}^{2+}$-induced mitoBK $\mathrm{Ca}$ channel activity ( $80 \%$ inhibition) more efficiently than NS1619-induced channel activity ( $50 \%$ inhibition) again indicating a non-specific uncoupling effect of NS1619 on isolated potato tuber mitochondria. The relationship between NS1619-induced IbTx-sensitive respiration and various IbTx concentrations reveals that $50 \%$ of maximal inhibition $\left(\mathrm{I}_{0.5}\right)$ by $\mathrm{IbTx}$ is reached at $615 \mathrm{nM}$, as calculated from the linear regression of a double reciprocal plot (Figure 3B, inset). A similar value was obtained when the effect of increasing IbTx concentration on $\Delta \Psi$ depolarization was analyzed (data not shown).

To exclude an influence of the applied modulators $\left(\mathrm{Ca}^{2+}, \mathrm{Ns} 1619, \mathrm{IbTx}\right)$ on succinate dehydrogenase activity, experiments were also performed with external NADH as a respiratory substrate (data not shown). The results confirm observations taken from the experiments described above (Figures 1-3).

The findings presented herein strongly suggest the presence of the $\mathrm{Ca}^{2+}$-activated potassium channel in the inner membrane of potato tuber mitochondria. To further test this hypothesis, we investigated the effect of $\mathrm{Ca}^{2+}$ and $\mathrm{IbTx}$ on isolated potato tuber mitochondria respiring (with succinate) in incubation media containing different monovalent cations (chloride salts) compared to those incubated in the presence of $\mathrm{K}^{+}$ (Figure 4) or in the absence of any monovalent cations. In medium deprived of monovalent cations, no $\mathrm{Ca}^{2+}$-induced $\mathrm{IbTx}$-sensitive increase in respiration and $\Delta \Psi$ depolarization were observed (data not shown). Figure 4 shows the influence of increasing concentrations (up to $50 \mathrm{mM}$ ) of $\mathrm{KCl}, \mathrm{NaCl}, \mathrm{LiCl}, \mathrm{RbCl}$, and $\mathrm{CsCl}$ on $\mathrm{Ca}^{2+}$-induced $\mathrm{IbTx}$-sensitive $\Delta \Psi$ depolarization (i.e., the difference between $\Delta \Psi$ in the presence of $0.8 \mathrm{mM} \mathrm{CaCl}_{2}$ and $\Delta \Psi$ in the presence of $\mathrm{CaCl}_{2}$ and $1.5 \mu \mathrm{M} \mathrm{IbTx}$ ). The results indicate that the influence of potassium channel modulators $\left(\mathrm{Ca}^{2+}\right.$ and $\left.\mathrm{IbTx}\right)$ on isolated potato tuber mitochondria in the above experiments can be significantly attributed to $\mathrm{K}^{+}$influx through the inner membrane.

Electrophysiological properties of mitoBK $_{\mathrm{Ca}}$ channel from the potato tuber mitochondrial membrane The inner mitochondrial membrane-enriched SMP from potato tuber mitochondria were reconstituted into PLMs. Incorporation of channels into the bilayer was usually observed within 10-20 min after SMP addition to the trans compartment. SMP fractions from five different preparations were used. More than 
140 reconstitutions were monitored in the single-channel experiments. Approximately $40 \%$ of the channels incorporated into bilayers showed properties of the large-conductance potassium channels. Figure 5 shows representative current-time traces (Figure 5B) and current-voltage relationship (Figure 5C) for potassium channel opening at different voltages in the $50 / 450 \mathrm{mM} \mathrm{KCl}$ (cis/trans) gradient solutions. The current was measured as a function of applied potential at intervals ranging from $+90 \mathrm{mV}$ to $-30 \mathrm{mV}$ (Figure 5C). The calculated ion conductance is equal to $502 \pm 15 \mathrm{pS}$ for potential from -30 to $20 \mathrm{mV}$ and $615 \pm 12 \mathrm{pS}$ for potential from +40 to $90 \mathrm{mV}$, thus indicating large-conductance potassium channel activity. The reversal potential of $+34 \mathrm{mV}$ calculated from curve fitting to the experimental data indicates that the examined ion channel is cation-selective. All incorporated large-conductance potassium channels were more active at positive than at $0 \mathrm{mV}$ potentials (Figure 5D). Sometimes we recorded spontaneous closing of channels at 0 $\mathrm{mV}$ and at negative potentials (Figure 5B). The activity of such channels could be rescued after applying positive potentials, for example $50 \mathrm{mV}$.

Substances known to modulate mammalian $\operatorname{mitoBK}_{\mathrm{Ca}}$ channel activity were used to examine the properties of the $\mathrm{K}^{+}$ion channel observed in our experiments. Figure 6 demonstrates the effect of $300 \mu \mathrm{M}$ $\mathrm{Ca}^{2+}$ on the potato tuber mitochondrial large-conductance potassium channels. Figure $6 \mathrm{~A}$ shows single channel recordings in the $50 / 450 \mathrm{mM} \mathrm{KCl}$ (cis/trans) gradient solutions at $0 \mathrm{mV}$, before and after addition of $\mathrm{Ca}^{2+} \cdot \mathrm{Ca}^{2+}$ caused a transition into an open state that indicates the existence of the mitoBK $\mathrm{Ca}$ channel in the potato tuber inner mitochondrial membrane. As depicted in the histograms shown in Figure $6 \mathrm{~B}$, the number of observations of the channel being in an open state changed from $73 \%$ to $86 \%$. The probability of channel opening $(\mathrm{P})$ at $0 \mathrm{mV}$ potential increased from $0.49 \pm 0.07$ to $0.84 \pm 0.05(n=4, \mathrm{p}<0.0076$, unpaired $t$ test) in the presence of $\mathrm{Ca}^{2+}$ (Figure 6C).

Figure 7 presents the inhibitory effect of IbTx on the potato tuber mitochondrial large-conductance potassium channels. As shown in the representative single channel recording obtained in $50 / 450 \mathrm{mM} \mathrm{KCl}$ (cis/trans) gradient solutions at $0 \mathrm{mV}$, before and after the addition of $600 \mathrm{nM} \mathrm{IbTx}$, the inhibitor caused a complete transition of the channel protein into a closed state (Figure 7A). The number of open state events changed from $83 \%$ to zero after IbTx addition, as illustrated in the histograms (Figure 7B). The probability of channel opening $(\mathrm{P})$ at $0 \mathrm{mV}$ potential decreased from $0.75 \pm 0.27$ for control recordings to $0.049 \pm 0.04$ after addition of $600 \mathrm{nM} \mathrm{IbTx}(\mathrm{p}<0.008$, unpaired $t$ test). Moreover, IbTx blocked the channel activity in a dose-dependent manner (in a range from 200 to $600 \mathrm{nM}$ ) (Figure 7C). The apparent concentration of IbTx that provided half maximal inhibition $\left(\mathrm{I}_{0.5}\right)$ was approximately $170 \mathrm{nM}$. In our PLM experiments, $25 \%$ of the channels with a large conductance did not display sensitivity to IbTx (data not shown).

\section{Immunological detection of plant mitoBK $K_{\mathrm{Ca}}$ channel proteins}

Immunoblotting of total mitochondrial proteins, as well as SMP, allowed immunological detection of the plant mitoBK $\mathrm{Ca}_{\mathrm{a}}$ channel. For this, antibodies raised against the mammalian plasma membrane $\mathrm{BK}_{\mathrm{Ca}}$ channel pore $\left(\alpha\right.$ subunit $\left.\mathrm{K}_{\mathrm{Ca}} 1.1\right)$ were used. In plant mitochondrial and SMP fractions, a protein band with a molecular mass of approximately $70 \mathrm{kDa}$ was detected using the anti- $\mathrm{K}_{\mathrm{Ca}} 1.1$ antibodies (Figure $8 \mathrm{~A}$ ). We also used antibodies raised against the mammalian plasma membrane $\mathrm{BK}_{\mathrm{Ca}}$ channel $\beta$ subunits. In potato tuber mitochondrial and SMP fractions, anti-slo $\beta 2$ antibodies cross-reacted with a single band at around 30 $\mathrm{kDa}$ (Figure 8B). Less sensitive reactivity was observed with anti-slo $\beta 1$ and anti-slo $\beta 4$ antibodies (data not shown). As shown in Figure 8, much stronger signals were obtained with SMP compared to isolated mitochondria using anti- $\mathrm{K}_{\mathrm{Ca}} 1.1$ and anti-slo $\beta 2$ antibodies, proving that the detected proteins localized to the inner membrane of potato tuber mitochondria. Moreover, specific blocking peptides blocked the antibodyantigen interaction, demonstrating the specificity of the reaction in the western blot analysis. On the other hand, mitochondrial (isolated mitochondria and SMP) and plasma membranes probed with antibodies to a plant plasma membrane marker $\left(\mathrm{H}^{+}\right.$-ATPase) displayed no signal in the mitochondrial fractions, indicating the absence of surface membrane contamination (Figure 8C). Therefore, we can conclude that the potato tuber mitoB $\mathrm{K}_{\mathrm{Ca}}$ channel may contain subunits similar to the $\alpha$ subunit $\mathrm{K}_{\mathrm{Ca}} 1.1$ and the $\beta$ subunit slo $\beta 2$. 


\section{DISCUSSION}

In the present study, we describe for the first time (to our knowledge) the functional properties of the mitoBK $_{\mathrm{Ca}}$ channel-like protein in plant mitochondria. Potassium channel activators, $\mathrm{Ca}^{2+}$ and NS1619, are able to modulate the resting respiratory rate (stimulation) and $\Delta \Psi$ (depolarization) in isolated potato tuber mitochondria. The opposite responses (respiratory rate inhibition and $\Delta \Psi$ repolarization) were observed when the mitoBK$_{\mathrm{Ca}}$ channel inhibitor, IbTx, was applied. These effects were dependent on the presence of $\mathrm{K}^{+}$in the incubation medium. Thus, we provide evidence that the observed effects of the mitoBK $\mathrm{Ca}_{\mathrm{C}}$ channel openers are due to activation of electrogenic potassium transport through the inner mitochondrial membrane, likely mediated by a potassium channel belonging to the family of mitochondrial potassium channels previously described in mammalian mitochondria [7,12].

This is the first study to investigate the electrophysiological properties of the large-conductance potassium channels in plant mitochondria. We used the planar lipid bilayers technique to confirm that large potassium channels are present in the potato tuber inner mitochondrial membrane. The cation selectivity, large conductance $(502-615 \mathrm{pS})$, reverse potential $(+34 \mathrm{mV})$ and sensitivity to $\mathrm{Ca}^{2+}$ and IbTx of the potato tuber mitoBK $\mathrm{Ca}$ channel indicate similarity to the mammalian mitoBK $\mathrm{Ca}$ channels previously reported in glioma [8], skeletal muscle [29], brain [30], and cardiac [31] mitochondria. However, the ion conductance of the potato tuber mitoBK $\mathrm{Ca}_{\mathrm{a}}$ channel $(502-615 \mathrm{pS})$ is higher than that observed for mammalian mitoBK $\mathrm{Ca}$ channels ( 260-300 pS). This could be due to highly active $\mathrm{K}^{+}$transport in some plant mitochondria, leading to enormous mitochondrial depolarization (also in potato tuber mitochondria) [14], which contrasts with mammalian mitochondria in which $\Delta \Psi$ dissipation seems to be weaker [32,33]. Moreover, mammalian plasma membrane $\mathrm{BK}_{\mathrm{Ca}}$ channel has a higher relative permeability for $\mathrm{Rb}^{+}$than for $\mathrm{Na}^{+}$[34] in contrast to that observed for potato tuber mitoBK $\mathrm{Ca}$ channel. However, $\mathrm{K}^{+}$flux is dominant.

In addition to the functional studies, the presence of mitoBK $_{\mathrm{Ca}}$ channel proteins in potato tuber mitochondria is indicated by their cross-reactivity with antibodies raised against the $\mathrm{K}_{\mathrm{Ca}} 1.1 \alpha$ subunit of the mouse $\mathrm{BK}_{\mathrm{Ca}}$ channel and the $\beta$ subunit of the human slo $\beta 2 \mathrm{BK}_{\mathrm{Ca}}$ channel. This suggests that the mitoBK $\mathrm{Ca}$ channel present in the potato tuber inner mitochondrial membrane may be structurally similar to the mammalian $\mathrm{BK}_{\mathrm{Ca}}$ channel. Namely, it may be formed by the principle pore-forming $\alpha$ subunit that interacts with an auxiliary $\beta 2$ subunit. The predominant $\beta 2$ subunit may determine the channel's activity, including its sensitivity to $\mathrm{Ca}^{2+}$ and other modulators. The relative molecular mass of the detected potato tuber proteins (around 70 and $30 \mathrm{kDa}$ for the $\alpha$ and $\beta 2$ subunits, respectively) differs from that of the mammalian proteins from plasma membrane ( 125 and $\sim 44 \mathrm{kDa}$ for the $\alpha$ and $\beta 2$ subunits, respectively) [35], while the molecular mass of the $\alpha$ subunit in mammalian mitochondria is variable, depending on tissue (55-125 $\mathrm{kDa})$ [31,36]. The $\beta 2$ subunit of mitoBK $\mathrm{Ca}_{\mathrm{a}}$ was detected in astrocyte mitochondria [37]. However, the molecular identity (gene and protein sequences) of the mammalian mitoBK $\mathrm{K}_{\mathrm{Ca}}$ channel is presently unknown. On the other hand, the molecular mass of the detected potato tuber mitoBK $\mathrm{Ca}_{\mathrm{Ca}}$ channel $\alpha$ subunit $(\sim 70 \mathrm{kDa})$ is similar to the plant potassium channel protein from the plasma membrane of Arabidopsis thaliana (76 kDa) [38].

Our results demonstrate the presence of a mitoBK $\mathrm{Ca}_{\mathrm{Ca}}$-channel in plant mitochondria that may function as a possible novel signaling link between intramitochondrial calcium levels and the mitochondrial membrane potential. Ion channels in the mitochondrial inner membrane influence cell function in specific ways that can be detrimental or beneficial to plant cell function. At least one type of potassium channel, the mitoK $\mathrm{K}_{\mathrm{ATP}}$ channel, has been described in plant mitochondria to date [14-17]. The physiological functions of the plant mitoK $_{\mathrm{ATP}}$ channel remain unclear. It may be involved in regulating mitochondrial volume [15], in programmed cell death (19), and/or in the prevention of reactive oxygen species formation $[14,20]$. The physiological role of the mitoBK $\mathrm{Ca}$ channel in the plant mitochondria described in this work, which seems to significantly modulate $\mathrm{K}^{+}$mitochondrial distribution, awaits exploration.

In summary, in the present study we identified and characterized a novel potassium channel of the inner membrane of potato tuber mitochondria. Pharmacological, biophysical, and molecular properties of the potato tuber mitochondrial potassium channel are similar to those of the well known mammalian plasma membrane $\mathrm{BK}_{\mathrm{Ca}}$, including: (i) potassium selectivity and activation by calcium ions and NS1619 (a BK $\mathrm{Ca}$ 
opener); (ii) inhibition by $\mathrm{IbTx}$ (a $\mathrm{BK}_{\mathrm{Ca}}$ blocker); (iii) biophysical properties of a large-conductance potassium channel; (iv) immunoreactivity with antibodies raised against $\alpha$ and $\beta$ subunits of the plasma membrane $\mathrm{BK}_{\mathrm{Ca}}$. These properties strongly suggest that a large-conductance calcium-activated potassium channel similar to that of mammalian mitochondria is present in plant mitochondria. The functional and immunoblotting data presented herein demonstrate for the first time the presence of a mitoBK $\mathrm{Ca}_{\mathrm{Ca}}$ channel in the inner membrane of plant mitochondria.

This work was supported by the Polish Mitochondrial Network MitoNet.pl and by the Nencki Institute of Experimental Biology. Partially the study was supported by grants from the Ministry of Science and Higher Education P-N/031/2006 and 3382/B/P01/2007/33.

\section{REFERENCES}

1. O'Rourke, B. (2004) Evidence for mitochondrial K+ channels and their role in cardioprotection. Circ. Res. 94, 420-432

2. Szewczyk, A., Jarmuszkiewicz, W. and Kunz, W.S. (2009) Mitochondrial potassium channels. IUBMB Life 61, 134-143

3. Szewczyk, A. (1998) The intracellular potassium and chloride channels: properties, pharmacology and function. Mol. Membr. Biol. 15, 49-58

4. Bernardi, P. (1999) Mitochondrial transport of cations: channels, exchangers, and permeability transition. Physiol. Rev. 79, 1127-1155

5. Szewczyk, A. and Wojtczak, L. (2002) Mitochondria as a pharmacological target. Pharmacol. Rev. 54, 101-127

6. Halestrap, A. P. (1994) Regulation of mitochondrial metabolism through changes in matrix volume. Biochem. Soc. Trans. 22, 522-529

7. Inoue, I., Nagase, H. Kishi, K. and Higuti, T. (1991) ATP-sensitive $\mathrm{K}^{+}$channel in the mitochondrial inner membrane. Nature 352, 244-247

8. Siemen, D., Loupatatzis, C., Borecky, J. Gulbins, E. and Lang, F. (1999) $\mathrm{Ca}^{2+}$-activated K channel of the BK-type in the inner mitochondrial membrane of a human glioma cell line. Biochem. Biophys. Res. Commun. 257, 549-554

9. Szabo, I., Bock, J. Jekle, A. Soddemann, M. Adams, C. Lang, F. Zoratti, M. and Gulbins, E. (2005) A novel potassium channel in lymphocyte mitochondria. J. Biol. Chem. 280, 12790-12798

10. Jarmuszkiewicz, W., Sluse-Goffart, CM., Vercesi, A.E. and Sluse, F.E. (2001) Alternative oxidase and uncoupling protein: thermogenesis versus cell energy balance. Biosci. Rep. 21, 213-222

11. Sluse, F.E. and Jarmuszkiewicz, W. (1998) Alternative oxidase in the branched mitochondrial respiratory network: an overview on structure, function, regulation, and role. Braz. J. Med. Biol. Res. 31, 733-747

12. Siedow, J.N. and Umbach, A.L. (2000) The mitochondrial cyanide-resistant oxidase: structural conservation amid regulatory diversity. Biochim. Biophys. Acta 1459, 432-439

13. Vercesi, A.E., Borecky, J., Maia, I.D., Arruda, P., Cuccovia, I,M. and Chaimovich, H. (2006) Plant uncoupling mitochondrial proteins. Annu. Rev. Plant Biol. 57, 383-404

14. Pastore, D., Stoppelli, M. C., Di Fronzo, N. and Passarella, S. (1999) The existence of the $\mathrm{K}^{+}$channel in plant mitochondria. J. Biol. Chem. 274, 26683-26690

15. Petrussa, E., Casolo, Y., Braidot, E., Chiandussi, E., Macri, F. and Vianello, A. (2001) Cyclosporin A induces the opening of a potassium-selective channel in higher plant mitochondria. J. Bioenerg. Biomembr. 33, 107-117

16. Chiandussi, E., Petrussa, E., Macri, F. and Vianello, A. (2002) Modulation of a plant mitochondrial $\mathrm{K}_{\text {ATP }}^{+}$channel and its involvement in cytochrome $c$ release. J. Bioenerg. Biomembr. 34, 177-184

17. Diolez, P. and Moreau, F. (1985) Correlations between ATP-synthesis, membrane potential and oxidation rate in plant mitochondria. Biochim. Biophys. Acta 806, 56-63 
18. Pastore, D., Trono, D., Laus, M. N., Di Fronzo, N. and Flagella, Z. (2007) Possible plant mitochondria involvement in cell adaptation to drought stress. A case study: durum wheat mitochondria. J. Exp. Bot. 58, 195-210.

19. Casolo, V., Petrussa, E., Krajnáková, J., Macrì, F. and Vianello, A. (2005) J. Exp. Bot. Involvement of the mitochondrial $\mathrm{K}_{\text {ATP }}^{+}$channel in $\mathrm{H}_{2} \mathrm{O}_{2^{-}}$or NO-induced programmed death of soybean suspension cell cultures. 56, 997-1006

20. Ruy, F., Vercesi, A.E., Andrade, P.B., Bianconi, M.L., Chaimovich, H. and Kowaltowski, A.J. (2004) A Highly active ATP-insensitive K+ import pathway in plant mitochondria. J. Bioenerg. Biomembr. 36, 195-202

21. Bednarczyk, P., Kicinska, A., Kominkova, V., Ondrias, K., Dołowy K. and Szewczyk, A. (2004) Quinine inhibits mitochondrial ATP-regulated potassium channel from bovine heart. J. Membr. Biol. 199, 63-72

22. Hordejuk, R., Lobanov, N. A., Kicinska, A., Szewczyk, A. and Dolowy, K. (2004) pH modulation of large conductance potassium channel from adrenal chromaffin granules. Mol. Membr. Biol. 21, 307313

23. Bednarczyk, P., Dołowy, K. and Szewczyk, A. (2005) Matrix $\mathrm{Mg}^{2+}$ regulates mitochondrial ATPdependent potassium channel from heart. FEBS Lett. 579, 1625-1632

24. Kamo, N., Muratsugu, M., Hongoh, R. and Kobatake, Y. (1979) Membrane potential of mitochondria measured with an electrode sensitive to tetraphenyl phosphonium and relationship between proton electrochemical potential and phosphorylation potential in steady state. J. Membr. Biol. 49, 105-121

25. Silva, M.A.P., Carnieri, E.G.S. and Vercesi, A.E. (1992) Calcium transport by corn mitochondria: evaluation of the role of phosphate. Plant Physiol. 98, 452-457

26. de Oliveira, H.C., Saviani, E.E., de Oliveira, J.F.P. and Salgado, I. (2007) Cyclosporin A inhibits calcium uptake by Citrus sinensis mitochondria. Plant Sci. 172, 665-670

27. Heinen, A., Camara, A.K.S., Aldakkak, M., Rhodes, S.S., Riess, M.L. and Stowe, D.F. (2006) Mitochondrial $\mathrm{Ca}^{2+}$-induced $\mathrm{K}^{+}$influx increases respiration and enhances ROS production while maintaining membrane potential. Am. J. Physiol. Cell Physiol. 292, C148-C156

28. Heinen, A., Winning, A., Shlack, W., Hellmann, M.W., Precel, B., Fraßdorf, J. and Weber, N.C. (2008) Physiological levels of glutamine prevent morphine-induced preconditioning in the isolated rat heart. Eur. J. Pharmacol. 578, 108-113

29. Skalska, J., Piwonska, M., Wyroba, E., Surmacz, L., Wieczorek, R., Koszela-Piotrowska, I., Zielinska, J., Bednarczyk, P., Dolowy, K., Wilczyński, G. M., Szewczyk, A. and Kunz, W. S. (2008) A novel potassium channel in skeletal müscle mitochondria. Biochim. Biophys. Acta 1777, 651-659

30. Skalska, J., Bednarczyk, P., Piwonska, M., Kulawiak, B., Wilczynski, G., Dolowy, K., Kudin, A. P., Kunz, W.S. and Szewczyk, A. (2009) Calcium ions regulate K uptake into brain mitochondria: the evidence for a novel potassium channel. Int. J. Mol. Sci. 10, 1104-1120

31. Xu ,W., Liu, Y., Wang, S., McDonald, T., Van Eyk, J.E., Sidor, A. and O'Rourke, B. (2002) Cytoprotective role of $\mathrm{Ca}^{2+}$-activated $\mathrm{K}^{+}$channels in the cardiac inner mitochondrial membrane. Science 298, 1029-1033

32. Debska, G., Kicinska, A., Skalska, J., Szewczyk, A., May, R., Elger, C.E. and Kunz, W.S. (2002) Opening of potassium channels modulates mitochondrial function in rat skeletal muscle. Biochim Biophys Acta 1556, 97-105

33. Debska, G., May, R., Kicińska, A., Szewczyk, A., Elger, C.E. and Kunz, W.S. (2001) Potassium channel openers depolarize hippocampal mitochondria. Brain Res, 892, 42-50

34. Blatz, A.L. and Magleby, K.L. (1984) Ion conductance and selectivity of single calcium-activated potassium channels in cultured rat muscle. J. Gen. Physiol. 84, 1-23

35. Wulf, H., Hay-Schmidt, A., Poulsen, A.N., Klaerke, D.A., Olesen, J. and Jansen-Olesen, I. (2009) Molecular investigations of $\mathrm{BK}(\mathrm{Ca})$ channels and the modulatory beta-subunits in porcine basilar and middle cerebral arteries. J. Mol. Histol. 40, 87-97 
36. Douglas, R.M., Lai, J.C.K., Bian, S., Cummins, L., Moczydlowski, E. and Haddad, G.G. (2006) The calcium-sensitive large-conductance potassium channel (BK/MAXI K) is present in the inner mitochondrial membrane of rat brain. Neuroscience 139, 1249-1261

37. Piwonska, M., Wilczek, E., Szewczyk, A. and Wilczyński, G.M. (2008) Diferential distribution of $\mathrm{Ca}^{2+}$-activated channel $\beta 4$ subunit in rat brain: immunolocalization in neuronal mitochondria. Neuroscience 153, 446-60

38. Reintanz, B., Szyroki, A., Ivashikina, N., Ache, P., Godde, M., Becker, D., Palme, K and Hedrich, R. (2002) AtKC1, a silent Arabidopsis potassium channel alpha -subunit modulates root hair K+ influx. Proc. Natl. Acad. Sci. USA 99, 4079-4084

\section{FIGURE LEGENDS}

Figure 1 Iberiotoxin-sensitive influence of $\mathrm{CaCl}_{2}$ on resting respiratory rate and membrane potential.

Mitochondria were incubated in a standard incubation medium additionally containing $50 \mathrm{mM} \mathrm{KCl}$. A, 5 $\mathrm{mM}$ succinate, $1.5 \mu \mathrm{M}$ IbTx and successive doses of $\mathrm{CaCl}_{2}$ were added as indicated. The dashed trace shows the measurement obtained in the absence of $\mathrm{Ca}^{2+}$. An example of three measurements (using mitochondria from three different preparations) is shown. Numbers on the traces refer to $\mathrm{O}_{2}$ consumption rates in $\mathrm{nmol} \mathrm{O} \times \mathrm{min}^{-1} \times \mathrm{mg}^{-1}$ protein or to $\Delta \Psi$ values in $\mathrm{mV} . B, \mathrm{Ca}^{2+}$-induced IbTx-sensitive respiration versus $\mathrm{CaCl}_{2}$ concentration. Inset, double reciprocal plot. $C$, D, effect of $\mathrm{CaCl}_{2}$ concentration on $\mathrm{O}_{2}$ consumption and $\Delta \Psi$ (respectively) in the presence or absence of $1.5 \mu \mathrm{M} \mathrm{IbTx}$. Course of the measurements as in $A$, except that IbTx was added prior to addition of $\mathrm{Ca}^{2+}$ where indicated. The data deal with three different mitochondrial preparations $( \pm$ S.D). $C$, the percentage of control respiration in the absence of modulators $\left(119 \pm 4 \mathrm{nmol} \mathrm{O} \times \mathrm{min}^{-1} \times \mathrm{mg}^{-1}\right.$ protein $) . D$, the change in $\Delta \Psi$ induced by a given concentration of $\mathrm{CaCl}_{2}$ relative to the initial state $4 \Delta \Psi(216 \pm 1 \mathrm{mV}$, S.D. $)$ in the absence of modulators.

Figure 2 Influence of NS1619, a mitoBK $K_{\mathrm{Ca}}$ channel activator, on resting respiratory rate and membrane potential. Mitochondria were incubated in a standard incubation medium additionally containing $50 \mathrm{mM} \mathrm{KCl}$. A, $5 \mathrm{mM}$ succinate, $1.5 \mu \mathrm{M} \mathrm{IbTx}$, and successive doses of NS1619 were added as indicated. The dashed trace shows the measurement obtained in the absence of activator. Numbers on the traces refer to $\mathrm{O}_{2}$ consumption rates in nmol $\mathrm{O} \times \mathrm{min}^{-1} \times \mathrm{mg}^{-1}$ protein or to $\Delta \Psi$ values in $\mathrm{mV}$. $B$, NS1619-induced IbTx-sensitive respiration versus NS1619 concentration. Inset, double reciprocal plot. $C$, $D$, effect of NS1619 concentration on $\mathrm{O}_{2}$ consumption and $\Delta \Psi$ (respectively) in the presence or absence of $1.5 \mu \mathrm{M} \mathrm{IbTx}$. Course of the measurements as in $A$, except that IbTx was added prior to activator addition where indicated. The data deal with three different mitochondrial respirations $( \pm$ S.D). $C$, the percentage of control respiration in the absence of modulators $\left(122 \pm 3 \mathrm{nmol} \mathrm{O} \times \mathrm{min}^{-1} \times \mathrm{mg}^{-1}\right.$ protein). $D$, the change in $\Delta \Psi$ induced by a given concentration of $\mathrm{CaCl}_{2}$ relative to the initial state $4 \Delta \Psi(217 \pm 1$ $\mathrm{mV}$, S.D.) in the absence of modulators.

Figure 3 Influence of iberiotoxin, a mitoBK $\mathrm{Ca}_{\mathrm{a}}$ channel inhibitor, on resting respiratory rate and membrane potential. Mitochondria were incubated in a standard incubation medium additionally containing $50 \mathrm{mM} \mathrm{KCl}$. A, $5 \mathrm{mM}$ succinate, $40 \mu \mathrm{M} \mathrm{NS1619}$, and successive doses of $0.5 \mu \mathrm{M}$ IbTx were added as indicated. The dashed trace shows the measurement in the absence of IbTx addition. Numbers on the traces refer to $\mathrm{O}_{2}$ consumption rates in $\mathrm{nmol} \mathrm{O} \times \mathrm{min}^{-1} \times \mathrm{mg}^{-1}$ protein or to $\Delta \Psi$ values in $\mathrm{mV}$. $B$, IbTx-sensitive NS1619-induced respiration versus the inhibitor concentration. Inset, double reciprocal plot. $C, D$, effect of IbTx concentration on $\mathrm{O}_{2}$ consumption and $\Delta \Psi$ (respectively) in the presence or absence of $0.8 \mathrm{mM} \mathrm{CaCl}_{2}$ or $40 \mu \mathrm{M} \mathrm{NS1619}$. Course of measurements as in $A$. The data deal with three different mitochondrial respirations $( \pm$ S.D). $C$, the percentage of control respiration in the absence of activators and IbTx $\left(120 \pm 4 \mathrm{nmol} \mathrm{O} \times \mathrm{min}^{-1} \times \mathrm{mg}^{-1}\right.$ protein $) . D$, the change in $\Delta \Psi$ induced by a given modulator relative to the initial state $4 \Delta \Psi(216 \pm 1 \mathrm{mV}$, S.D. $)$. 
Figure 4 Cation selectivity; influence of cations on $\mathrm{Ca}^{2+}$-induced $\mathrm{IbTx}$-sensitive resting respiratory rate and membrane potential. Mitochondria were incubated in a standard incubation medium, except that $3 \mathrm{mM} \mathrm{NaH}_{2} \mathrm{PO}_{4}$ was replaced with $3 \mathrm{mM}$ TrisH $\mathrm{PO}_{4}$. Increasing concentrations of $\mathrm{KCl}, \mathrm{NaCl}, \mathrm{LiCl}$, $\mathrm{CsCl}$, or $\mathrm{RbCl}(10-50 \mathrm{mM})$ were obtained by successive additions once a steady-state $\Delta \Psi$ had been established. The dilution effect of salt addition was taken into account. The change in $\Delta \Psi$ induced by a given chloride salt relative to the initial state $4 \Delta \Psi(216 \pm 1 \mathrm{mV}$, S.D. $)$ is shown as the difference between $\Delta \Psi$ measured in the presence of $0.8 \mathrm{mM} \mathrm{CaCl}_{2}$ and $\Delta \Psi$ measured in the presence of $\mathrm{CaCl}_{2}$ and $1.5 \mu \mathrm{M}$ IbTx.

Figure 5 Single channel recordings of large-conductance potassium channels from potato tuber mitochondria in planar lipid bilayers. $A$, Schematic configuration of the cis and trans compartments used in the experiments. Reconstitution of inner mitochondrial membranes into planar lipid bilayers was performed as described under "Experimental Procedures". B, Single channel current-time recordings in $50 / 450 \mathrm{mM} \mathrm{KCl}$ (cis/trans) gradient solutions at different voltages. "_" indicates current during the closed state of the channel. An example of each of eight measurements is shown. $C$, current-voltage (I/V) characteristics of single-channel events in $50 / 450 \mathrm{mM} \mathrm{KCl}($ cis/trans $)$ gradient solutions $(n=12)$ at different voltages. $D$, probability of channel opening $(\mathrm{P})$ at two different voltages, 0 and $50 \mathrm{mV}$ (mean \pm SEM, $n=3$ ).

Figure 6 Effects of $\mathrm{Ca}^{2+}$ on the activity of large-conductance potassium channels from potato tuber mitochondria. $A$, an example of the single channel recordings in 50/450 $\mathrm{mM} \mathrm{KCl} \mathrm{(cis/trans)} \mathrm{gradient}$ solutions at $0 \mathrm{mV}$ under control conditions and after addition of $300 \mu \mathrm{M} \mathrm{Ca}^{2+}$ to the cis and trans compartments $(n=4)$. "“-" indicates current during the closed state of the channel. $B$, amplitude histograms measured in the absence and presence of $300 \mu \mathrm{M} \mathrm{Ca}^{2+}$. All points shown in the amplitude histograms were fitted by two Gaussian distributions. The closed state corresponds to the peak at $0 \mathrm{pA}, \mathrm{O}$ - open state, $\mathrm{C}$ - closed state. $C$, Probability of channel opening (P) at $0 \mathrm{mV}$ potential. The average of four different experiments $( \pm$ SEM $)$ is shown.

Figure 7 Effects of IbTx on the activity of large-conductance potassium channels from potato tuber mitochondria. $A$, an example of single channel recordings in 50/450 $\mathrm{mM} \mathrm{KCl} \mathrm{(cis/trans)} \mathrm{gradient}$ solutions at $0 \mathrm{mV}$ under control conditions and after addition of $600 \mathrm{nM}$ IbTx to the cis and trans compartments. "-“ indicates current during the closed state of the channel. $B$, amplitude histograms from a control experiment and after addition of $600 \mathrm{nM} \mathrm{IbTx}$. All points shown in the amplitude histograms were fitted by two Gaussian distributions. The closed state corresponds to the peak at $0 \mathrm{pA}, \mathrm{O}$ - open state, $\mathrm{C}-$ closed state. $C$, Probability of channel opening (P) at $0 \mathrm{mV}$ potential. Data from eight experiments in which different concentrations of $\mathrm{IbTx}$ were used are presented as means \pm SEM.

Figure 8 Western blot analysis of potato tuber fractions with anti- $\mathrm{K}_{\mathrm{Ca}} 1.1(A)$ and anti-sloß2 (B) antibodies raised against the mammalian $B K_{C a}$ channel proteins in the absence or presence of a specific blocking peptide. $C$, Detection of $\mathrm{H}^{+}$-ATPase. Mito - mitochondria, SMP - submitochondrial particles, PM - plasma membrane-enriched fraction. Different amounts of protein were loaded into each lane (as indicated). Examples of 3-4 immunoblots (using samples from different preparations) are shown. 
Fig. 1.

A.

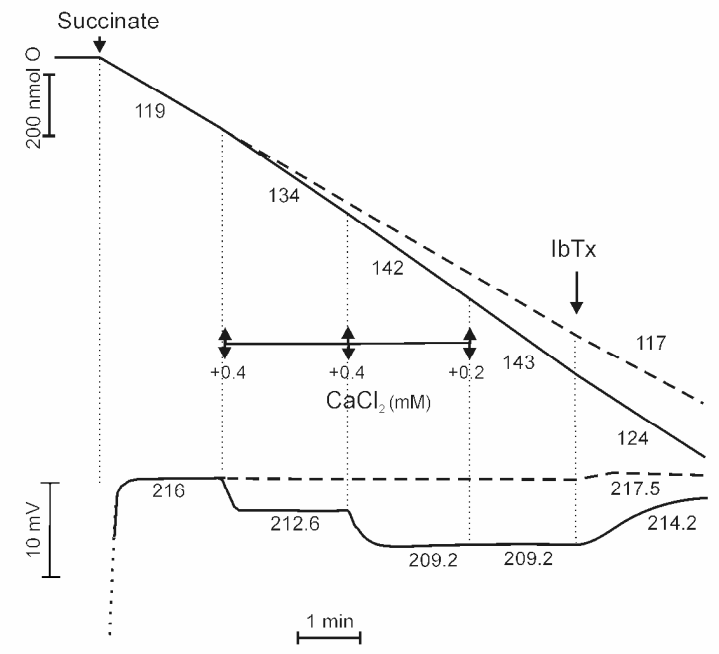

C.

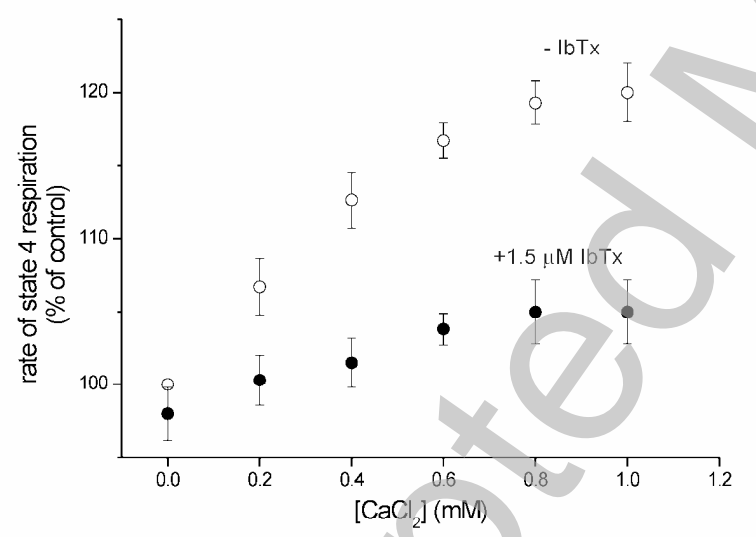

B.

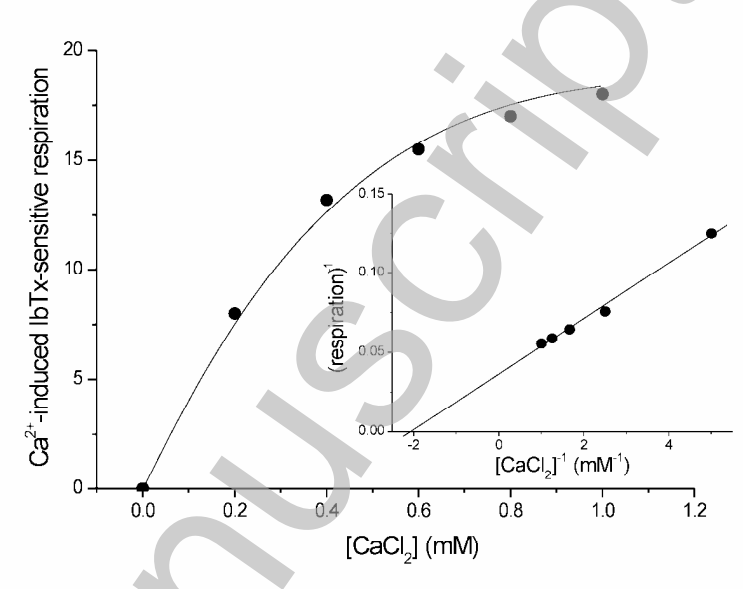

D.

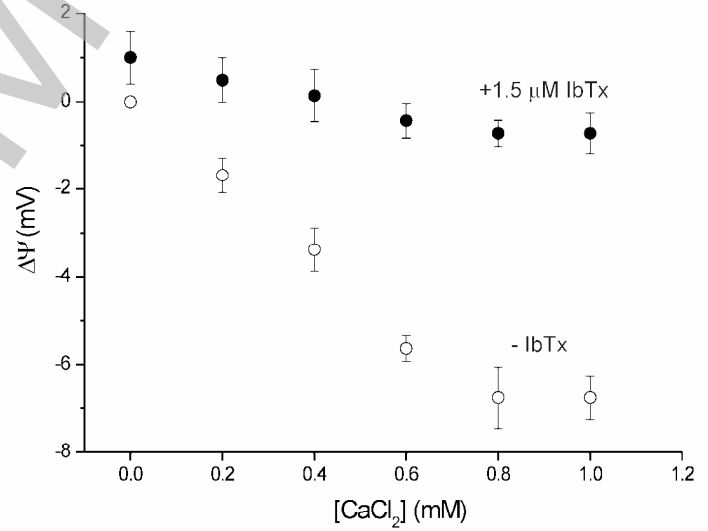


Fig. 2.

A.

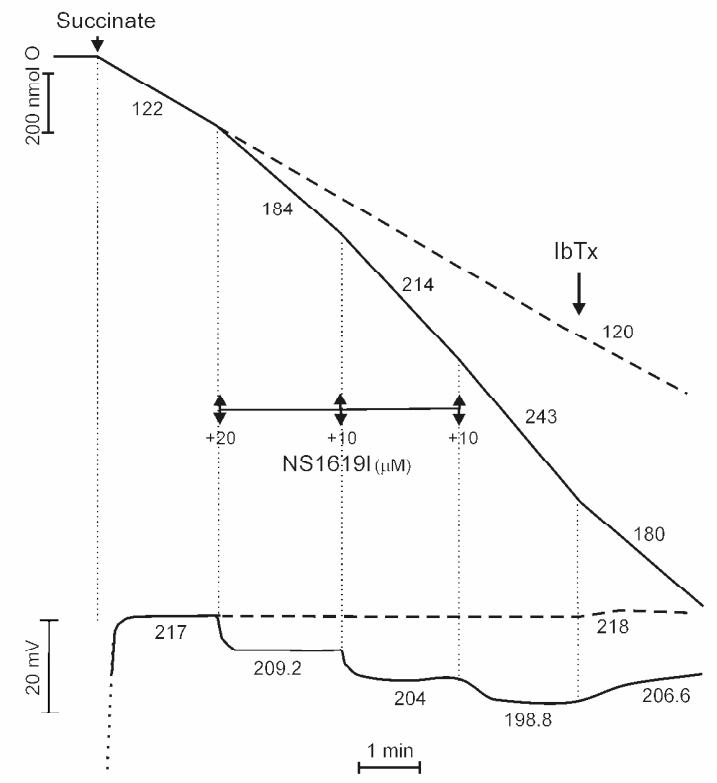

C.

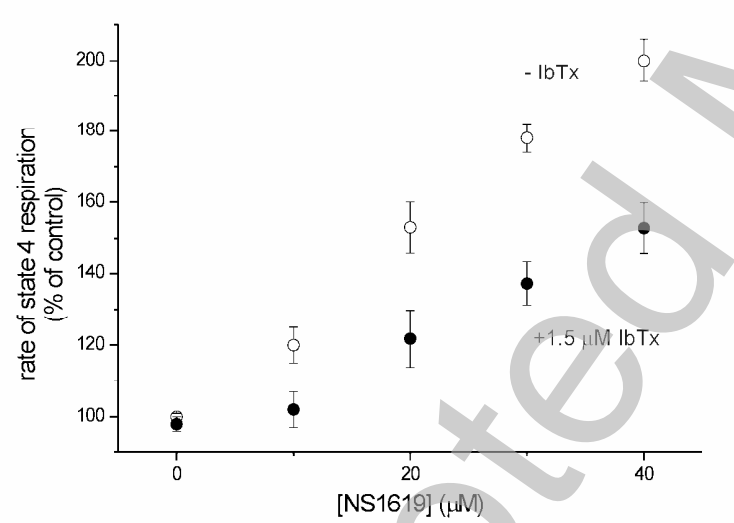

B.

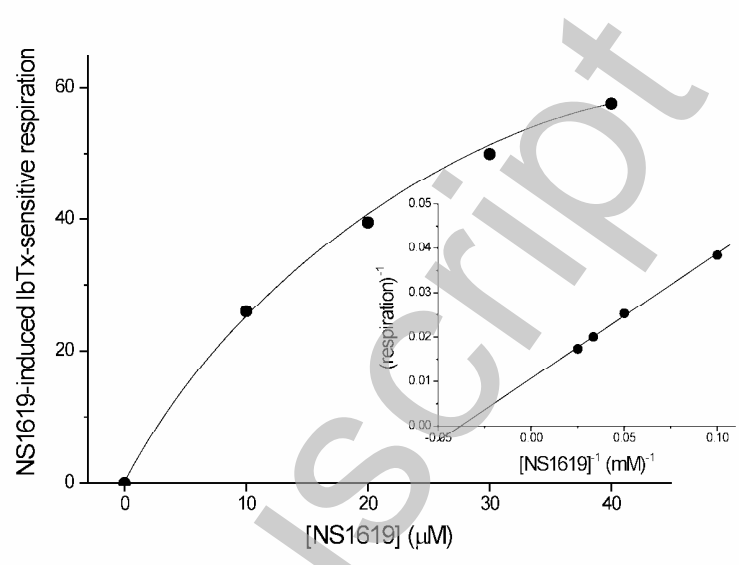

D.

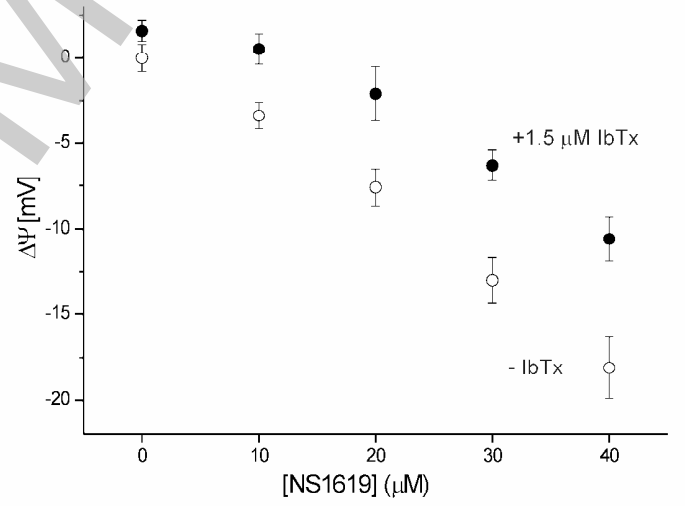


Fig. 3.

A.

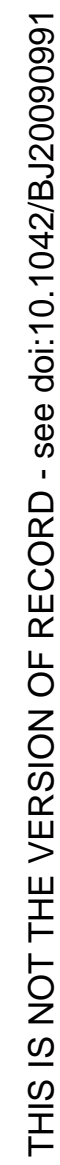

C.
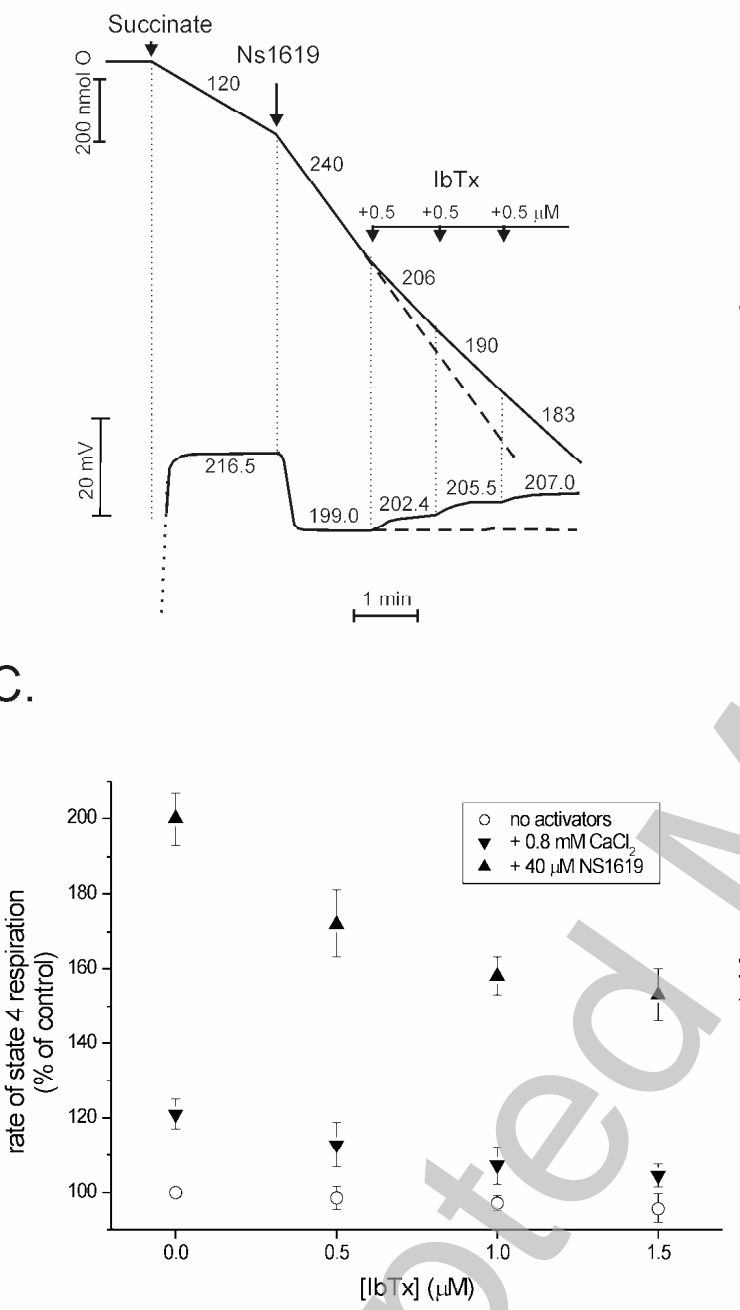

B.

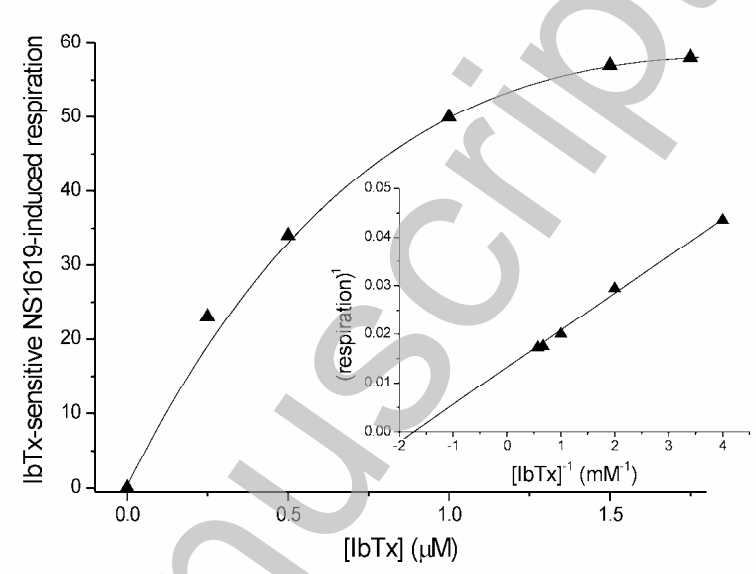

D.

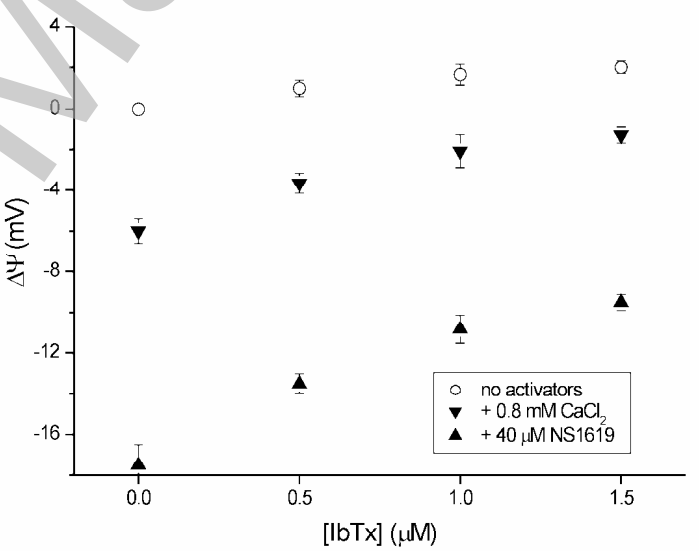


Fig. 4.

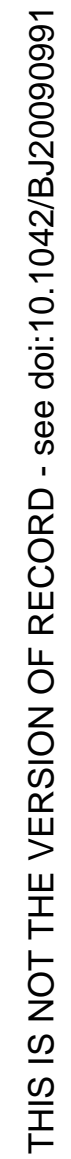

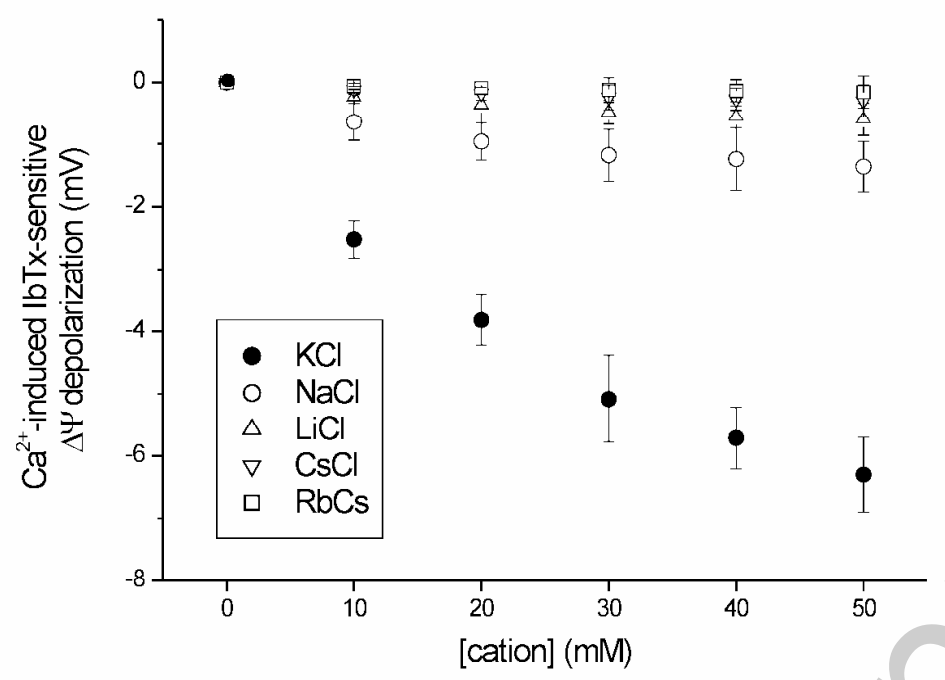


Fig. 5.

A.

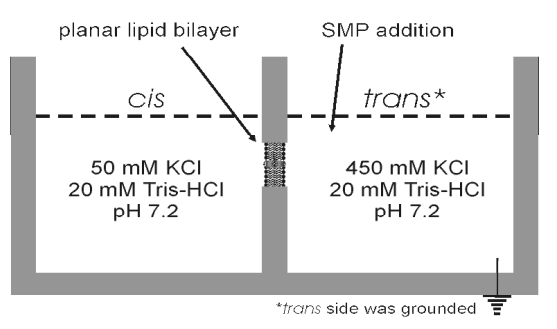

C.

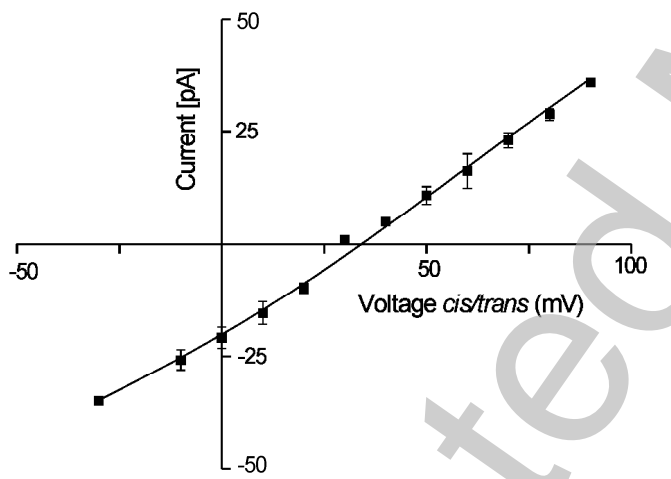

B.

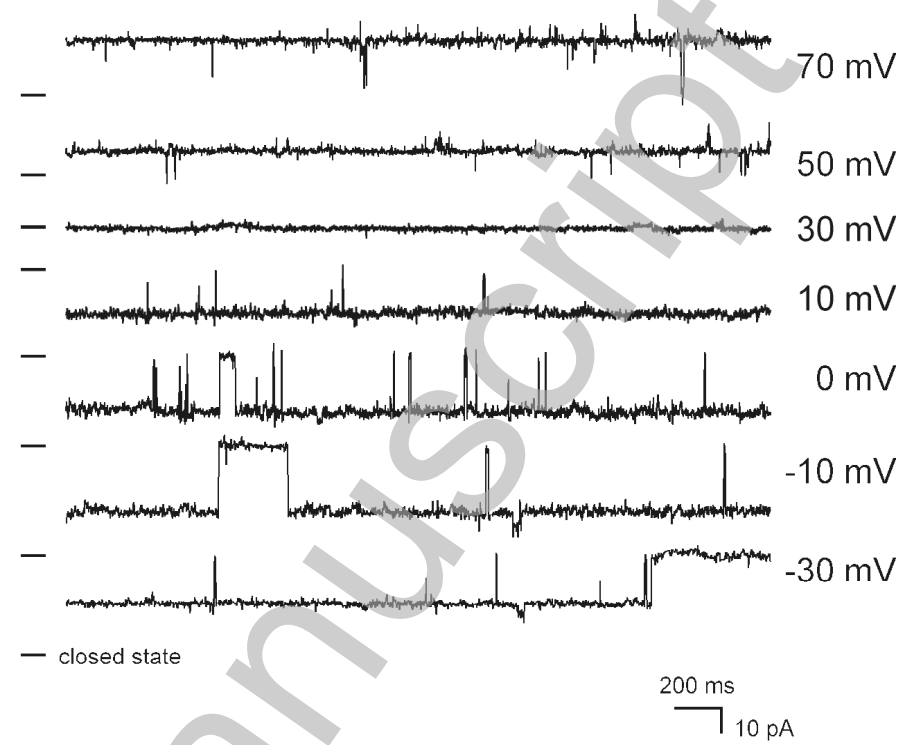

D.

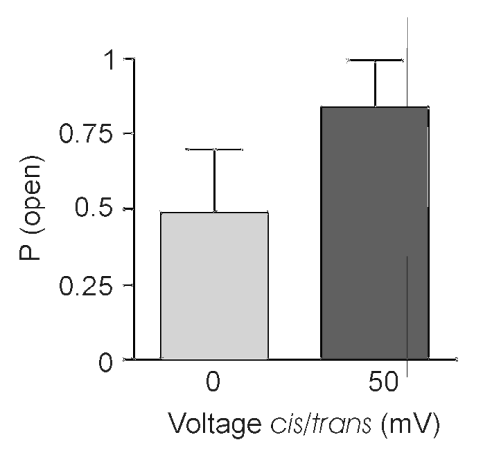


Fig. 6.

A.

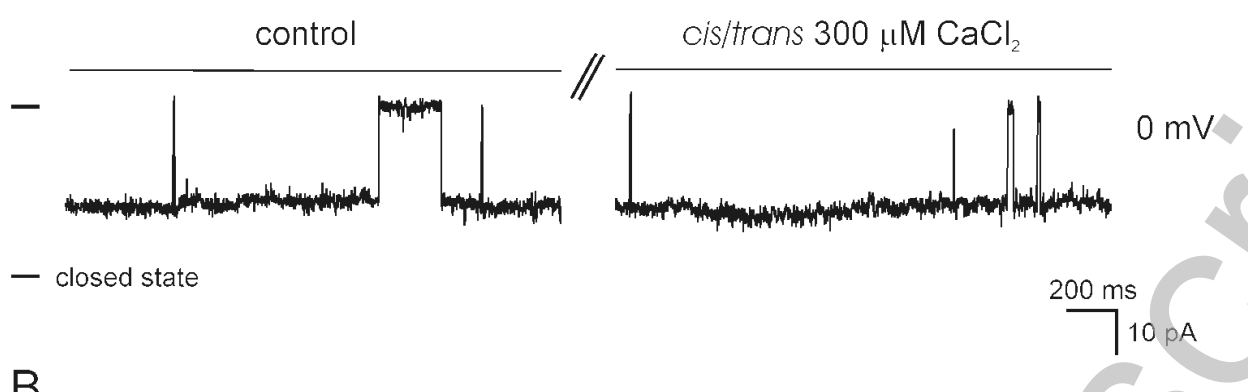

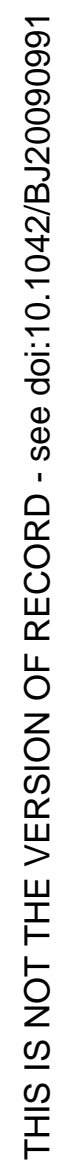
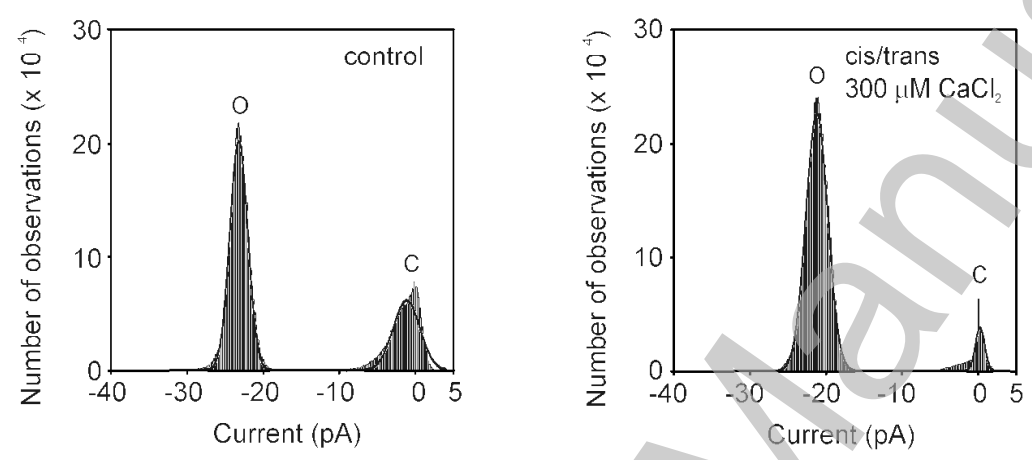

C.

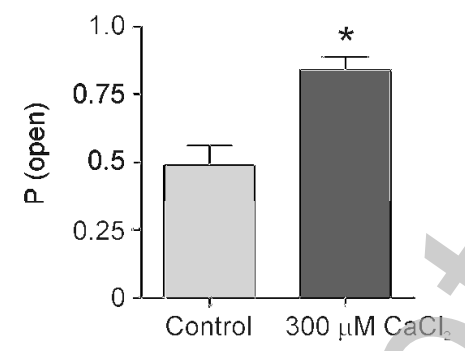


Fig. 7

A.

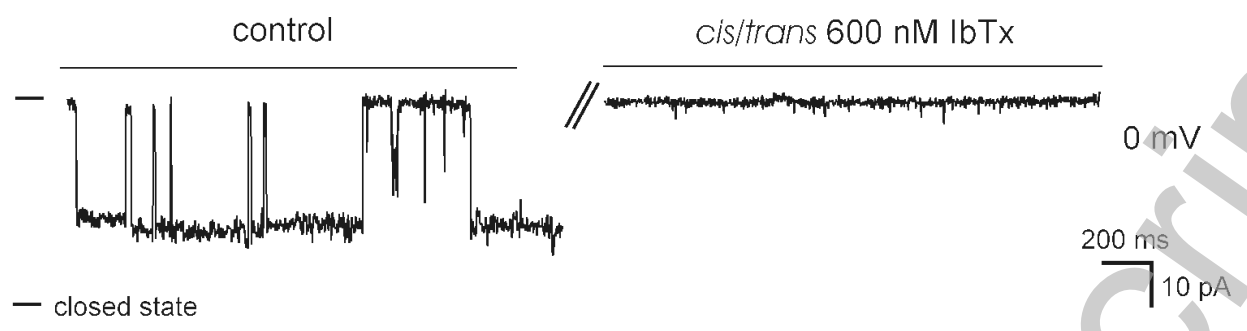

B.
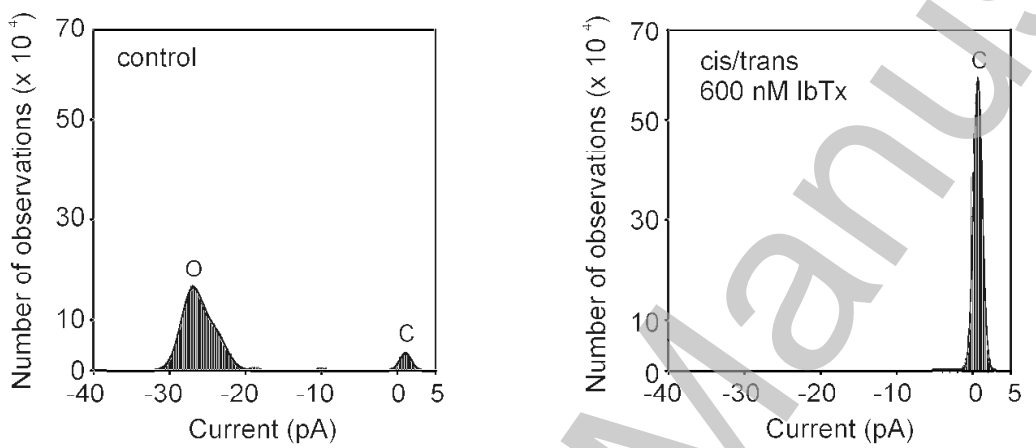

C.

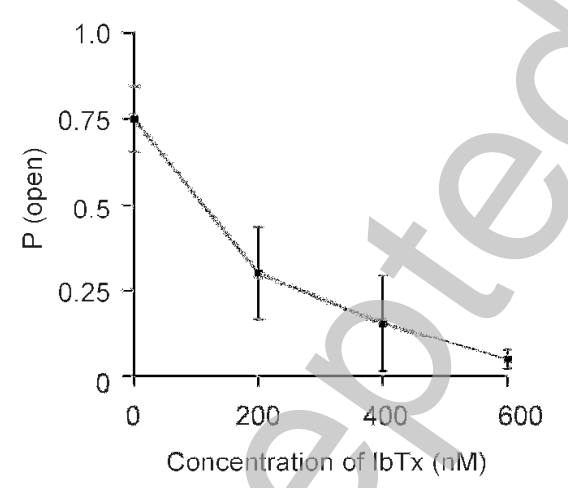


Fig. 8 .

A.

C.

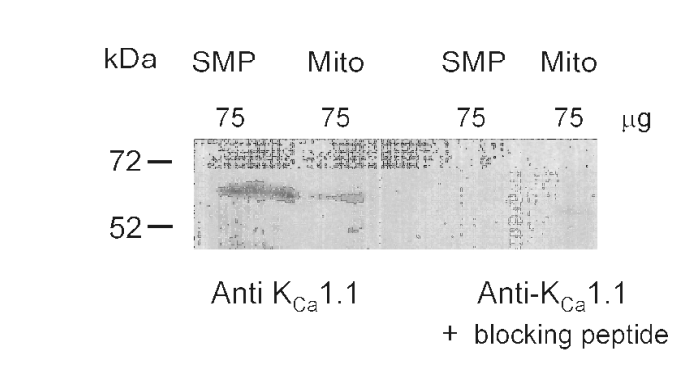

kDa SMP Mito SMP Mito
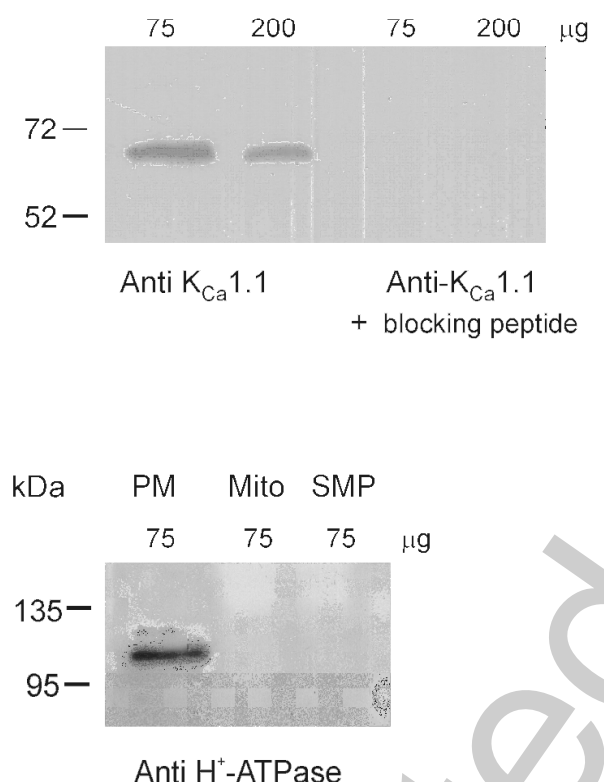

B.

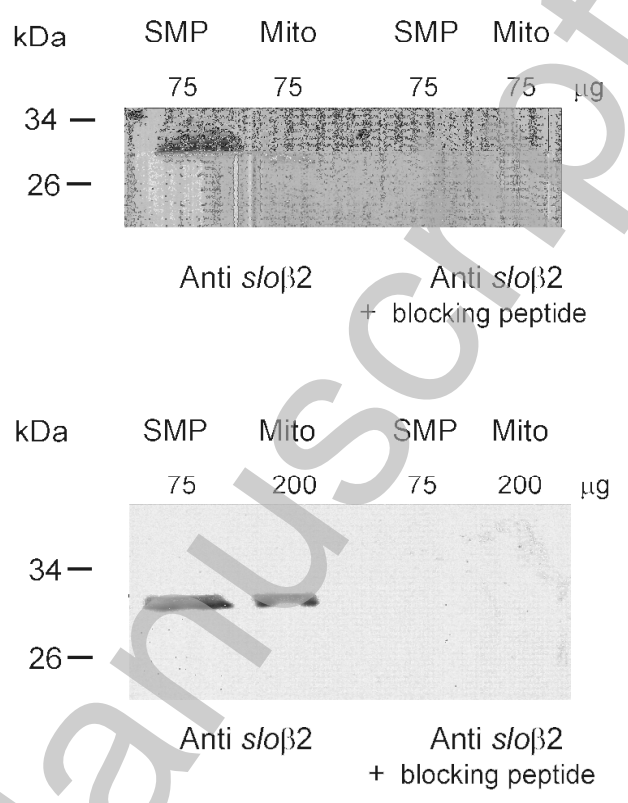

